\title{
AOR
}

Selected Papers of \#AoIR2019:

The $20^{\text {th }}$ Annual Conference of the

Association of Internet Researchers

Brisbane, Australia / 2-5 October 2019

\section{THE VISCERAL EMBODIMENT OF DIGITAL PLEASURES}

\section{Introductory Statement}

This panel explores digital pleasures through entanglement of bodies and digital technologies. It focuses on the digital structures and affordances that facilitate seeking, receiving and giving pleasure. The panel brings together four presentations, all of which speak to the central conference theme by considering how the architectures that afford digital pleasures also raise attendant questions of trust and risk in digital systems.

We analyse the ways in which intimacy is not only interactive, but also profoundly embodied. Haraway's work in particular highlights the importance of taking seriously the nexus of human bodies and technologies and attending to the ways in which technologies not only deliver and mediate pleasure, but potentially expand upon our capacity to experience it.

To date the research corpus has largely focused upon the micro-social interactions of digital intimacies (Dobson, Robards, and Carah 2018). This emphasis on relational intimacy puts the body into the background of the digitally mediated encounter and limits the ways in which we can talk about embodiment, sex and pleasure online.

This panel is a timely body of work which draws together important threads in internet research, that is how the body, pleasure and digital spaces are closely intertwined. Our arguments are predicated on two conceptual apparatuses: affordances (Davis and Chouinard 2016) from science and technology studies (STS) and role-taking (Mead 1934) from social psychology. In the opening paper, Davis sets a theoretical frame that moves beyond evaluations of veracity and authenticity to consider the variability and subjectivity of mediated pleasure (Mediated Pleasure: STS meets Social Psychology). This framing concretises visceral and ephemeral experiences.

We argue that mediated practices engage the body as a site of pleasure and embodied affective intensity. Within this frame, we suggest that digitally mediated pleasures, while widely consumed, still have a hint of the 'fringe' or 'subversive'. To understand trust and risk, we argue that we need to understand both the ways in which people use digitally mediated space for a variety of practices and the architecture of these spaces.

Our empirical papers consider different types of digital pleasure from sex to drugs and sound.

The first empirical paper argues that physical proximity is not a necessary condition of sex or sex work. Cam workers trade in erotic pleasures that are, by definition, mediated and remote. As a sex work practitioner, advocate, and public scholar, the Patella-Rey paints a

Suggested Citation (APA): Smith, N., Davis, J., Maddox, A., Patella-Rey, P. (2019, October 2-5). The Visceral Embodiment of Digital Pleasures. Panel presented at AolR 2019: The 20th Annual Conference of the Association of Internet Researchers. Brisbane, Australia: AolR. Retrieved from http://spir.aoir.org. 


\section{AOR}

Selected Papers of \#AoIR2019:

The $20^{\text {th }}$ Annual Conference of the Association of Internet Researchers Brisbane, Australia / 2-5 October 2019

picture of carefully crafted intimacies that are driven by and result in pleasurable sexual encounters.

Distinctly, digital drugs are evoked through binaural beats. They are an emergent property of the affordances of audio technologies and human bodies in which the human body converges as a socio-technical assemblage through which pleasure is experienced. Maddox and Barratt argue that despite the obvious implications for harm reduction there is also the potential for a moral panic (Cohen 2002; Young 1971) surrounding the ways that these digital pleasures move bodies beyond the bounds of social control.

Similarly, ASMR becomes tangible as an emergent property of human and technical assemblages. The primary attraction of ASMR is the embodied, physical pleasure of sound. Smith argues that while ASMR does trade partly in relational intimacy, its affective stickiness (Ahmed 2004) comes from physical pleasure.

Embodied pleasure is intrinsic to the human condition, and digital media is deeply embedded in contemporary life. How these intersect is a key piece of the puzzle of what it means to be human in contemporary society. We argue that embodied pleasures are under researched in the social sciences and there is a lack of literature that considers the role that technology plays in the affordance of pleasure despite its imbrication with these practices.

\section{References}

Ahmed, S. (2004). The Cultural Politics of Emotion. Edinburgh: Edinburgh University Press.

Cohen, S. (2002). Folk Devils and Moral Panics (3rd ed.). New York, London: Routledge.

Davis, J. and Chouinard, J. (2016). Theorizing Affordances: From Request to Refuse, Bulletin of Science, Technology and Society, 36(4): 241-246. doi: 10.1177/0270467617714944.and

Dobson, A.S., Robards B.R., and Carah, N. (2018). Digital Intimate Publics and Social Media. Switzerland: Palgrave Macmillan

$\mathrm{S}$

Haraway, D (1991). "A Cyborg Manifesto: Science, Technology, and SocialistFeminism in the Late Twentieth Century". In D. Haraway, Simians, Cyborgs and Women: The Reinvention of Nature. London: Routledge.

Mead, G. H. (1934). Mind, Self and Society, Vol. 111: Chicago: University of Chicago Press. 


\section{AOR}

Selected Papers of \#AoIR2019: The $20^{\text {th }}$ Annual Conference of the Association of Internet Researchers Brisbane, Australia / 2-5 October 2019

Young, J. (1971). The Drugtakers. London: Paladin. 


\section{AOR}

Selected Papers of \#AolR2019:

The $20^{\text {th }}$ Annual Conference of the

Association of Internet Researchers

Brisbane, Australia / 2-5 October 2019

\section{MEDIATED PLEASURE: STS MEETS SOCIAL PSYCHOLOGY}

Jenny Davis

The Australian National University

Pleasure is intrinsically embodied. Nerve endings, synapses, blood flow, and body fluids are recruited by aural, visual, olfactory, tactile, gustatory, and vestibular encounters. Physical co-presence between bodies and stimuli is not a precondition for pleasure's activation. Rather, pleasure can be mediated and indirect. This is evidenced by historical markets for meditative recordings that induce relaxation, phone sex operators that excite, and cooking shows that bring salivary glands alive. Digital technologies, in turn, have exploded as conduits of pleasure. ASMR, food porn, sex camming, and digital drugs, alongside pimple popping, massage videos, and the pleasurable-by-design 'ping' of social media notifications together show a warm and fleshy relationship between people, platforms, and machines (Allen 2017, Garcia-Argibay, Santed and Reales 2018, Jones 2016, Smith and Snider 2019, Versace et al. 2018). The aim of this paper is to give theoretical grounding to the phenomenon of digitally mediated embodied pleasure.

Digitally mediated pleasure is a visceral entanglement between technology and subjectivity. I suggest theorizing digitally mediated pleasure through two conceptual apparatuses: affordances from science and technology studies (STS) and role-taking from social psychology. Affordances refer to the ways technical design features enable and constrain social outcomes (Gibson 1986, Norman 1998). Role-taking is a classic concept from social psychology that refers to putting the self in another's position (Mead 1934) through processes of empathy and perspective taking (Davis and Love, 2017). Affordances and role-taking converge to provide a social reading of technical systems through which bodily pleasure is achieved in the context of indirect, mediated, impersonal, and remote stimuli.

Affordance analysis of digitally mediated pleasure investigates how design architectures open and constrict pleasurable bodily experiences. The mechanisms and conditions framework of affordances (Davis and Chouinard 2016) is particularly useful in this regard. The mechanisms and conditions framework approaches technical artifacts as dynamic and variable in their effects. Under this model, artifacts request, demand, encourage, discourage, refuse and allow particular user capabilities and related social outcomes. How a given artifact affords varies across subjects and circumstances. The mechanisms and conditions framework can chart the technical features that support and constrain pleasurable experiences, for whom, and under what conditions. 


\section{AOR}

Selected Papers of \#AolR2019: The $20^{\text {th }}$ Annual Conference of the Association of Internet Researchers Brisbane, Australia / 2-5 October 2019

Role-taking makes sense of mediated pleasure as a process by which subjects transport the self into an imagined body, with visceral effect. Role-taking incorporates cognitive processes of perspective taking and affective processes of empathy. Perspective taking entails imagining what the other thinks and feels. Empathy entails a subject feeling with the other, moved by the other's emotions (Davis and Love, 2017). Digitally mediated experiences of pleasure can thus be read as embodied role-taking. Those who experience pleasure through digital configurations of sensory stimuli are placing themselves in the heart, mind, and/or flesh of another in ways that elicit bodily response. This "other" may be an avatar, a person on a screen, or even the imagined self.

Weaving together role-taking and affordances, the following question emerges: what are the social and technical conditions that facilitate embodied role-taking?

Answering this question requires a baseline assumption of variability in both affordances and role-taking. This variability bears out through theoretical and empirical advances in STS and social psychology. Technical features afford differently for different subjects and across circumstances (Davis and Chouinard, 2016). Similarly, some subjects role-take more effectively than others (Love and Davis 2014). Concretely, this assumption of variability indicates that some subjects will experience digitally mediated embodied pleasure with great ease, while others will not experience it at all; some technical features will elicit embodied pleasure more readily, others with more difficulty, and these will vary across persons and situations. Digitally mediated pleasure thus starts from a place of experiential diversity at the intersection of technologies, bodies, and social psychological processes. From this intersection we can address questions about the conditions under which pleasure manifests, does not manifest, and takes diverse form.

Bringing together theories of STS and social psychology provides a scaffold for understanding phenomena-such as digitally mediated pleasure-for which the technical and visceral intertwine. The structural and dynamic nature of the conceptual tools selected herein-affordances and role-taking-sidestep questions of veracity and authenticity with regard to mediated pleasure and instead, attend to questions about how it all works, for whom, and under what circumstances. Such questions are critical as subjects pursue pleasure through technical means, entrusting deep intimacies to remote content creators, mass-produced devices, and corporate supported platforms.

\section{References}

Allen, M. (2017). "Sean Parker Unloads on Facebook: "God Only Knows What It's 


\section{AOR}

Selected Papers of \#AoIR2019: The $20^{\text {th }}$ Annual Conference of the Association of Internet Researchers Brisbane, Australia / 2-5 October 2019

Doing to Our Children's Brains."." Retrieved: 02/23/2019).

(https://www.axios.com/sean-parker-unloads-on

facebookgodonlyknowswhatitsdoing-to-our-childrens-brains-1513306792-f855e7b4

4e99-4d608d51-2775559c2671.html)

Davis, J.L and Love, T.P. (2017). "Self-in-Self, Mind-in-Mind, Heart-in-Heart: The Future of Role-Taking, Perspective Taking, and Empathy." Pp. 151-74 in Advances in Group Processes: Emerald Publishing Limited.

Davis,J.L. and Chouinard J.B.. (2016)."Theorizing

Affordances: From Request to Refuse." Bulletin of Science, Technology and Society 36(4):241-48.

Garcia-Argibay, M., Santed, M.A. and Reales, J.M. (2018).

"Efficacy of Binaural Auditory Beats in Cognition, Anxiety, and Pain Perception: A Meta-Analysis." Psychological Research:1-16.

Gibson, JJ. (1986). The Ecological Approach to Visual Perception: Lawrence Erlbaum Associates.

Jones, A. (2016). "“I Get Paid to Have Orgasms": Adult Webcam Models' Negotiation of Pleasure and Danger." Signs: Journal of Women in Culture and Society 42(1):227-56.

Love, T.P. and Davis, J.L. (2014). "The Effect of Status on Role-Taking Accuracy." American Sociological Review 79(5):848-65.

Mead, G.H. (1934). Mind, Self and Society, Vol. 111. Chicago: University of Chicago Press.

Norman, D.A. (1998). The Design of Everyday Things. London: MIT.

Smith, N. and Snider, AM. 2019. "ASMR, Affect and Digitally-Mediated Intimacy." Emotion, Space and Society 30:41-48.

Versace, F., Frank, D.W., Stevens, E.M.,

Deweese, M.M., Guindani, M. and Schembre, S.M. (2018). "The Reality of "Food

Porn": Larger Brain Responses to Food-Related Cues Than to Erotic Images Predict Cue-Induced Eating." Psychophysiology:e13309. 


\title{
AOR
}

Selected Papers of \#AoIR2019:

The $20^{\text {th }}$ Annual Conference of the

Association of Internet Researchers

Brisbane, Australia / 2-5 October 2019

\section{INTIMACY WITH STRANGERS: A STUDY OF DIGITALLY MEDIATED RELATIONSHIPS IN SEX CAM MODELING}

\author{
PJ Patella-Rey \\ University of Maryland
}

\begin{abstract}
Sex is an intrinsically embodied act that, paradoxically, is flourishing on the screens of our digital devices. In particular, sex camming has become a thriving industry. Cam models and their clients interact across a range of platforms including specialized sites and conventional social media. The shared sexual experience between cam models and clients is at once intimate, physical, and mediated. Through interviews with models working in the pornography industry, I examine the way digital mediation not only enables, but at times deepens, embodied pleasure and emotional connection.
\end{abstract}

Discussion of the growing role of digital technology in our lives has often centered on fears that "real" intimate relationships are being undermined by substituting them with something inferior, simulated, and shallow. For example, Turkle's (2012: 12) best-seller Alone Together, pivots on the question: "Does virtual intimacy degrade our experience of the other kind and, indeed, of all encounters, of any kind?". Earlier research (tracing back to a 1998 study by Kraut et al.) repeatedly sought to explore whether the supposed substitutions of online interaction for offline interaction left us feeling more isolated.

These fears about the real being supplanted by simulation also carry over into the sexual sphere. McGlotten (2013: 2) observed that "Utopian cyberspace discourses... were always tempered by technophobic panics that turned on questions of intimacy, especially of the more carnal sort." But, as many researchers have noted (e.g., Baym, 2015; Wellman and Rainie, 2012; Stone, 1994; Dibbel, 1993), people can and do experience meaningful and intimate interactions mediated through digital technologies, and, for some users, this also extends to sexual interactions. While most often, digitally-mediated intimacy is experienced with the people we also interact with offline, sometimes, intimacy emerges in relationships that exist exclusively online.

Part of the difficulty in understanding these interactions is that intimacy is assumed to be closely tied to both proximity and familiarity. But, theoretical work by Simmel and others suggests that social and spatial distance can facilitate their own unique forms intimacy. Conversations with strangers on buses or airplanes may exemplify the sort of intimacy that can emerge in low-stakes relationships (de Sousa, 1991). Sex work researchers studying stripping and prostitution suggest that client-provider 


\section{AOR}

Selected Papers of \#AoIR2019:

The $20^{\text {th }}$ Annual Conference of the Association of Internet Researchers Brisbane, Australia / 2-5 October 2019

interactions are also instances where this sort of "bounded" intimacy can occur (Bernstein, 2007; Frank, 1998). In these cases, intimacy occurs while people are physically proximate, despite social distance (i.e., weak ties) between them.

Based in interviews with 33 sex cam models, my research examines interactions on cam sites where clients and providers are (at least, initially) both physically and socially distant from one another. Despite these conditions, my respondents overwhelmingly report deep intimacy with some clients-both in terms of information disclosure (Zelizer 2005, 2000; Simmel, n.d./1950) and in terms of mutual affirmation (Baym, 2018; Beebe et al. 2010). Most cam models do not interpret distance as an obstacle to overcome but as something that facilitates these relationships. In fact, models often employ sophisticated "distancing strategies" (Sanders, 2005; Brewis and Linstead, 2000) to maintain safe and comfortable separation, even as they seek to deepen sexual and emotional intimacy. This suggests that intimacy and proximity can exist in a dialectical relationship that is far more complex than what many tech researchers and commentators have assumed.

Despite a lack of physical proximity, bodily pleasure obviously remains central. Cam sites do, in fact, afford an intimate knowledge of the bodies of providers and also, often, clients. Many clients pay to have their bodies scrutinized by purchasing "cock ratings" from providers. Also, common practices like remote controlled sex toys and the purchase of used clothing add a dimension of indirect or virtual touch to the experience. More crudely, the same is true of "cum tributes" were a viewer ejaculates on the image of a provider (sometimes produced for that purpose). These examples demonstrate how digital mediation affords not only social connections but also unique kinds of back-and-forth interactions between bodies.

\section{References}

Baym, N. K. (2018). Playing to the crowd: Musicians, audiences, and the intimate work of connection. NYU Press.

Baym, N. K. (2015). Personal connections in the digital age. 2nd Edition. John Wiley and Sons.

Beebe, S. A., Beebe, S. J., and Redmond, M. V. (2010). Interpersonal Communication: Relating to Others. $6^{\text {th }}$ ed. Boston: Pearson.

Bernstein, E., (2007). Temporarily yours: Intimacy, authenticity, and the commerce of sex. Chicago: University of Chicago Press. 


\section{AOR}

Selected Papers of \#AolR2019: The $20^{\text {th }}$ Annual Conference of the Association of Internet Researchers Brisbane, Australia / 2-5 October 2019

Brewis, J., and Linstead, S. (2000). 'The worst thing is the screwing'(1): Consumption and the management of identity in sex work. Gender, Work and Organization, 7(2): 84-97.

de Sousa, R. (1991). "Love as Theater." The Philosophy of "Erotic" Love. Eds. R.C. Solomon and K. Higgins. Lawrence: University of Kansas Press.

Dibbell, J. (1993). A rape in cyberspace or how an evil clown, a Haitian trickster spirit, two wizards, and a cast of dozens turned a database into a society. Village Voice, 471.

Frank, K. (1998). The Production of Identity and the Negotiation of Intimacy in aGentleman's Club'. Sexualities, 1(2): 175-201.

Kraut, R., Patterson, M. et al.(1998). Internet Paradox: A Social Technology that Reduces Social Involvement and Psychological Well-Being? American Psychologist, 53(9): 1017-1031.

McGlotten, S. (2013). Virtual intimacies: Media, affect, and queer sociality. New York, New York: Suny Press.

Rainie, L., and Wellman, B. (2012). Networked: The new social operating system. MIT Press.

Sanders, T. (2005). 'It's just acting': sex workers' strategies for capitalizing on sexuality. Gender, work and organization, 12(4), 319-342.

Simmel, G. (n.d./1950). "The isolated individual and the dyad." The Sociology of Georg Simmel. Free Press, New York, pp.118-144.

Simmel, G. (1906). "The Sociology of Secrecy and of Secret Societies." Trans. Albion W. Small. American Journal of Sociology 11: 441-498

Stone, A. R. (1994). Split subjects, not atoms; or, how I fell in love with my prosthesis. Configurations, 2(1): 173-190.

Turkle, S. (2011/2017). Alone Together: Why We Expect More from Technology and Less from Each Other. New York: Basic Books.

Zelizer, V. A. (2005). The Purchase of Intimacy. Princeton, NJ: Princeton University Press. 


\section{AOR}

Selected Papers of \#AoIR2019: The $20^{\text {th }}$ Annual Conference of the Association of Internet Researchers Brisbane, Australia / 2-5 October 2019

Zelizer, V. A. (2000). The purchase of intimacy. Law and Social Inquiry, 25(3): 817848. 


\title{
AOR
}

Selected Papers of \#AoIR2019:

The $20^{\text {th }}$ Annual Conference of the

Association of Internet Researchers

Brisbane, Australia / 2-5 October 2019

\section{DIGITAL DRUGS: EMBODIED SOCIAL PRACTICES, PLATFORM AFFORDANCES, AND RESEARCH DIRECTIONS}

\author{
Alexia Maddox \\ Deakin University \\ Monica Barratt \\ Social and Global Studies Centre, RMIT \\ Conjoint, National Drug and Alcohol Research Centre, UNSW Sydney
}

This paper discusses and situates the emerging phenomenon of i-dosing and digital drugs. I-dosing is the experience of consuming digital drugs that are engendered through binaural beats and bodily practices. They are accessed through platforms such as audio/visual social media such as YouTube and SoundCloud and music streaming Apps such as Apple Music.

The paper will do two things, it will examine the bodily practices of i-dosing in which the digital artefact and the body harmonise to evoke the pleasure of drug taking. This discussion seeks to move beyond a critique of how platforms shape embodied pleasure to the transformed third space that emerges through the digital-body instrument. Secondly it will examine the politics that pleasures from consuming digital drugs provokes.

I-dosing is the sonic consumption of binaural beats, some of which are designed to engender the embodied experience of recreational drugs. Garcia-Argibay, Santed and Reales (2018) describe binaural beats as a perceptual phenomenon that occurs when presenting two tones separately to each ear that slightly differ in their frequency. LaLiberty (2017) extends this definition to note that the listener will also hear a psychoacoustically engendered third tone which is purported to "entrain" brain waves and incite cognitive and mental states. He observes from this phenomenon that the beat does not exist external to its listener, but only in the passage between the body and audio object. In their recent meta-analysis Garcia-Argibay et al. (2018) found growing evidence that binaural-beat exposure is an effective way to affect cognition. This finding suggests some potential of this audio technology as a digital drug and that the body is co-involved in both creating and experiencing the effect.

The term i-dosing appears to be marketing terminology derived from the platform IDoser, which first launched in 2005. I-Doser is an internet application for purchasing audio content that is claimed to simulate specific mental states through the use of binaural beats, some of which are named after prohibited recreational drugs (Fawzi and Mansouri 2017; LaLiberty 2017). Bhatia et al. (2016) in their description of the 


\section{AOR}

Selected Papers of \#AoIR2019: The $20^{\text {th }}$ Annual Conference of the Association of Internet Researchers Brisbane, Australia / 2-5 October 2019

rising phenomenon of digital drugs suggest that this is the 'dark side' of binaural beats, in which people may reach a subconscious state by listening to these beats. Within the geo-cultural context of their work, Fawzi and Mansouri argue that I-dosing is a serious growing issue for their community in Saudi Arabia.

Digital drugs are currently defined by Cornford and Lichtner (2014) from an STS perspective as 'drugs that are both dependent on and substantially constituted by multiple digital representations and connections, and whose use and effectiveness is strongly mediated through digital means'. This socio-material approach moves beyond the 'drugs as a technology and technology as a drug' (Walsh 2011) conceptualisation prevalent within the literature on the intersections of the internet and drugs. We argue however that this definition needs further refinement to encompass the practice of i-dosing through the removal of material caveats.

In this paper we suggest that the definition of digital drugs can be expanded to address the role of binaural beats in psychologically simulating the experience of drugs through auditory modes of delivery and their imbrication with uses of social media and smart device applications. To this end, we consider the literature connected to technologies for mood enhancement (Wadley 2016) and draw upon the work of Kane Race (2017) to incorporate thinking on drug use and embodied pleasure. These associations across complementary literature raise questions of trust in the platform, trust in the drug design and composition, and trust in the experience. In addition, considerations of vulnerability to psycho-social risks are raised by the possibility of recreational tinkering with brain waves to achieve states of embodied pleasure.

In order to articulate relationships between drug use, binaural beats, the body and the platform, we situate this paper within research exploring the affordances of the internet upon access to drugs. We also consider the ways that people who use drugs engage with online drug discussion for identity building, trip reports, harm reduction and community experience through text-based websites, such as online forums (Barratt and Lenton 2013), and audio-visual social media such as YouTube (Manning 2013).

Previously, we have explored how the affordances of the internet have facilitated drug access, such as through drug cryptomarkets (Barratt et al. 2016, Barratt and Maddox 2016, Maddox et al 2016). In that study, we interviewed people who used cryptomarkets to purchase drugs in order to understand its impact on their drug use trajectories. During these interviews, a participant shared their drug-related creative works, including a Soundcloud link to short music tracks based upon binaural beats they had composed while affected by the novel substances methoxetamine and 4fluoroamphetamine and 3-4 methylenedioxymethamphetamine (mdma, 'Ecstasy'). 


\section{AOR}

Selected Papers of \#AolR2019: The $20^{\text {th }}$ Annual Conference of the Association of Internet Researchers Brisbane, Australia / 2-5 October 2019

In this paper we present a profile of this participant's use of drugs, their socio-cultural referents, and their emobidied relationships to binaural beats, creativity and mindstate induction. The analysis will then be used to frame an ensuing discussion of the embodied pleasure that emerges through platform-to-body entrainment. We examine the bodily practices of i-dosing in which the digital artefact and the body harmonise to evoke the pleasure of drug taking, which we refer to as platform-body entrainment.

\section{References}

Bhatia, P., Rasal,S., Shelar, S.T. and Mulik, V.T, (2016). Binaural beats "Amenable or not", International Journal of Current Research, 8(08): 35960-35962.

Barratt, M. J., and Lenton, S. (2013). "Drugs and the internet". In A. Ritter, T. King, and M. Hamilton (Eds.), Drug use in Australian society. 272-293. Melbourne: Oxford University Press.

Barratt, M. J., and Maddox, A. (2016). "Active engagement with stigmatised communities through digital ethnography". Qualitative Research. 16(6): 701-19. doi:10.1177/1468794116648766.

Barratt, M. J., Lenton, S., Maddox, A., and Allen, M., (2016)."'What if you live on top of a bakery and you like cakes?'- Drug use and harm trajectories before, during and after the emergence of Silk Road". International Journal of Drug Policy, September 2016 35:50-57 http://dx.doi.org/10.1016/j.drugpo. 2016.04.006

Cornford, T. and Lichtner, V. (2014) "Digital drugs: An anatomy of new medicines." In: Doolin, B, Lamprou, E, Mitev, N and McLeod, L, (eds.) Information Systems and Global Assemblages. (Re)Configuring Actors, Artefacts, Organizations. IFIP WG 8.2 Working Conference on Information Systems and Organizations 2014, 11-12 Dec 2014, Auckland, New Zealand. Springer Verlag. 146-162. ISBN 9783662457078

Fawzi, M. M., and Mansouri, F. A. (2017). "Awareness on Digital Drugs Abuse and its Applied Prevention Among Healthcare Practitioners in KSA." Arab Journal of Forensic Sciences and Forensic Medicine (AJFSFM), 1:6.

Garcia-Argibay, M., Santed, M. A., and Reales, J. M. (2018). Efficacy of binaural auditory beats in cognition, anxiety, and pain perception: a meta-analysis. Psychological Research. doi:10.1007/s00426-018-1066-8

I-Doser.com - Want to Get High? (2019, 18 February). Retrieved from http://www.idoser.com 


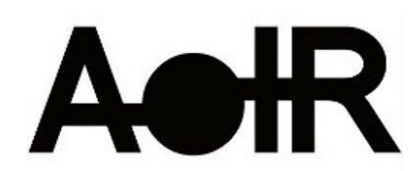

Selected Papers of \#AolR2019: The $20^{\text {th }}$ Annual Conference of the Association of Internet Researchers Brisbane, Australia / 2-5 October 2019

LaLiberty, R. (2017). 'Audio Acid: Affective Design and the Psychoacoustic Trip', Journal of Sonic Studies, 14.

https://www.researchcatalogue.net/view/291802/291803/0/23 [accessed 18/02/2019]

Maddox, A, Barratt, M, Lenton, S, and Allen, M., (2016), 'Constructive activism in the dark web: cryptomarkets and illicit drugs in the digital "demimonde", Information Communication and Society, 19(1): 111-126. DOI:

10.1080/1369118X.2015.1093531.

Manning, P. (2013) 'YouTube, 'drug videos' and drugs education”, Drugs: Education, Prevention and Policy, 20(2):, 120-130, DOI: 10.3109/09687637.2012.704435

Race, K. (2017). "Thinking with pleasure: Experimenting with drugs and drug research". International Journal of Drug Policy, 49, 144-149.

https://doi.org/10.1016/j.drugpo.2017.07.019

Wadley, G. (2016). "Mood-enhancing technology". Proceedings of the 28th Australian Conference on Computer-Human Interaction. 326-332. ACM. https://people.eng.unimelb.edu.au/gwadley/pubs/Wadley(2016)MoodEnhancingTech nology.pdf

Walsh, C. (2011). "Drugs, the Internet and Change", Journal of Psychoactive Drugs, 43(1): 55-63, DOI: 10.1080/02791072.2011.566501

\section{THE CURIOUS CASE OF ASMR: SOUND, PLEASURE AND MEDIATION}

Naomi Smith

Federation University 


\section{AOR}

Selected Papers of \#AolR2019: The $20^{\text {th }}$ Annual Conference of the Association of Internet Researchers Brisbane, Australia / 2-5 October 2019

The ASMR (Autonomous Sensory Meridian Response) community is organised around watching and creating videos of soundscapes that may induce 'tingling' physiological responses. In addition to the physical tingling sensation, definitions of ASMR created by the community focus on the state of relaxed euphoria it induces. These definitions further state that ASMR is triggered by small and otherwise mundane noises, including whispering, soft talking, typing, tapping, and crinkling sounds. With its focus on the mundane and often overlooked sounds of everyday life, such as crinkling, tapping, typing, and brushing, ASMR highlights the ways in which embodied and pleasurable affective moments inhabit the small spaces of social life. The internet has enlarged these small spaces and allowed for ASMR to be named, defined and circulated as an embodied, pleasurable and intentional affective experience constructed through sound.

ASMR has flourished in the digital space afforded by YouTube (Burgess et al. 2009). The ability to search, personally archive, and stream related videos suggested by YouTube has meant that the platform was a natural fit for the growing online community, allowing users to discover new ASMR content through the videos suggested by YouTube's recommender system. The comments sections of YouTube also allows watchers to provide feedback to the ASMR artists about 'good' triggers, as well as providing content creators with a way to track the popularity of their videos (Mardsen 2012). These engagements produce a seemingly endless archive of possible ASMR triggers and actively refine the concept of ASMR itself.

This research focused on understanding how ASMR is defined by the community that produces it, and by extension how we understand ASMR as a social phenomenon. These two research aims guided our sampling and analytic strategy. As it is not possible to watch every ASMR video produced, we focused our initial sampling on popular and active ASMR artists with YouTube channels. We have focused on ASMR artists with a strong public profile and a large online following, specifically those who have given media interviews and participate in raising the public profile of ASMR. From this group, we further analysed selected videos that directly describe the sensation of ASMR (as opposed to focusing on inducing it) or discuss ASMR sensitivity or immunity. This content seeks to explore and explain how ASMR 'works' and provide an 'oral history' of ASMR online before it became a recognisable community on YouTube.

The introduction of mediation to the ASMR experience highlights how digital technologies can be used to recreate and transmit embodied affective responses. The digital technologies implicated in ASMR have provided a space for it to emerge as a mediated and asynchronous experience by design, mediated by non-human agents, and like a film, re-watched and (re)experienced, again and again. Embodied affective experiences online are not static sites of engagement, but rather 


\section{AOR}

Selected Papers of \#AolR2019: The $20^{\text {th }}$ Annual Conference of the Association of Internet Researchers Brisbane, Australia / 2-5 October 2019

transmitted, circulated and shared. As Ahmed (2004: 45-46) argues, they are "not contained within the contours of the subject." Rather they exist outside and between users' subjectivities. The digitally mediated space that ASMR inhabits encourages us to think of ASMR as an 'affective genre' (Berlant 2008) located within structures of feelings (Williams 1977).

It also calls attention to the ways in which affect may be inorganically structured through digital technologies and the objects that are used to create ASMR, demonstrating that objects can "generate and transmit affects themselves" (Ash 2015: 85). The implication of the non-human in embodied, affective pleasures is also consistent with scholars (e.g. Kunstmans 2012: Paasonen 2015) who emphasise the sensory qualities of digital affectivities and intensities. Experiences such as ASMR provide us with a way to read senses and by extension the body, back into digitalised affectivities, as new media and digitisation expand the senses and the capacities of the biological body (Clough 2008). The digital space of the internet functions then as a "site of translation" (Ash 2015: 87), where affective pleasures can be "produced and translated into different states and forms for different purposes".

The intimate, embodied, affective experience produced by ASMR is not a site without tension and risk. In order to create and maintain the ASMR community, viewers and the creators of ASMR content engage in boundary work or boundary policing; a practice which has long been noted (e.g. Erikson 1996) as central to the maintenance of communities, both on and offline. In online spaces such as the ASMR community, boundary policing, or boundary work can take a variety of forms.

ASMR artists frequently emphasise that the ASMR experience is not intended for sexual pleasure, focusing instead on relaxation, stress and anxiety management (Andersen 2015: 692). The 'tingling' physiological response that comprises ASMR and the intimate, personal nature of the videos often means that ASMR is interpreted as sexual or erotic. However, the community's focus on the neuroscience of ASMR as deep relaxation, and more closely linked to meditation, is a way of foreclosing erotic interpretations. While this is partly due to the stigma that surrounds sex work, it is also a practical decision for ASMR creators. Positioning ASMR as relaxing, not sexual or erotic allows ASMR artists to continue to monetise their ASMR work while avoiding legislation like SESTA that holds online publishers liable for the content on their sites.

Sound provides insight in 'reciprocal affective and emotional relations between bodies, objects, places and ideas' (Doughty et al. 2016: 39), and ASMR is one such example of how sounds, as mediated by digital spaces like YouTube, co-create 


\section{AOR}

Selected Papers of \#AoIR2019: The $20^{\text {th }}$ Annual Conference of the Association of Internet Researchers Brisbane, Australia / 2-5 October 2019

embodied affective intensities. ASMR demonstrates the complexities that surround the intersections of pleasure embodiment, and digital mediation. The complex ways in which affect works through and with digital technologies illuminate the "'not yet' of a body's doing" (Gregg and Seigworth 2010: 4).

\section{References}

Ahmed, S. (2004). The Cultural Politics of Emotion. Edinburgh: Edinburgh University Press.

Andersen, J. (2015). 'Now You've Got the Shiveries Affect, Intimacy, and the ASMR Whisper Community', Television and New Media, 16(8), 683-700.

https://doi.org/10.1177/1527476414556184

Ash, J. (2015). 'Technology and affect: Towards a theory of inorganically organised objects', Emotion, Space and Society, 14, 84-90.

https://doi.org/10.1016/j.emospa.2013.12.017

Berlant, L. (2008). The Female Complaint: The Unfinished Business of Sentimentality in American Culture. Durham and London: Duke University Press.

Burgess, J., Green J., Jenkins H., and J. Hartley (2009). YouTube: Online Video and Participatory Culture. Cambridge, UK: Polity.

Clough, P. (2008). 'The Affective Turn: Political Economy, Biomedia and Bodies', Theory, Culture and Society, 25(1): 1-22. doi: 10.117/0263276407085156.

Doughty, K., Duffy, M., Harada, T. (2016). 'Practices of emotional and affective geographies of sound', Emotion, Space and Society, 20: 39-41.

doi:10.1016/j.emospa.2016.06.007

Erikson, K. (1966). Wayward Puritans: A Study in the Sociology of Deviance. New York: John Wiley

Gregg, M. and Seigworth G. (2010). The Affect Theory Reader, Durham and London: Duke University Press.

Kuntsman, A. (2012). Introduction, in A. Karatzogianni and A. Kuntsman, Digital Cultures and the Politics of Emotion: Feelings, Affect and Technological Change, pp 1-21, New York Palgrave MacMillian. 


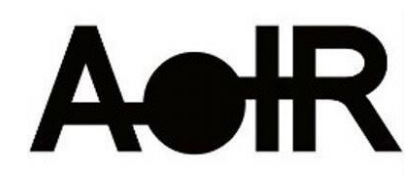

Selected Papers of \#AoIR2019: The $20^{\text {th }}$ Annual Conference of the Association of Internet Researchers Brisbane, Australia / 2-5 October 2019

Marsden, R. (2012). 'Maria Spends 20 Minutes Folding Towels:" Why Millions are Mesmerised by ASMR Videos', Independent, July 20, Available at:

www.independent.co.uk/life-style/gadgets-and-tech/features/maria-spends-20minutes-folding-towels-why-millions-are-mesmerised-by-asmr-videos-7956866.html (accessed 10 August 2017).

Paasonen, S. (2015). A Midsummer's Bonfire: Affective Intensities of Online Debate, In S. Paasonen, K. Hillis, and M. Petit (eds.) Networked Affect, Cambridge, Mass.: The MIT Press, pp.43-58. 